\title{
Preserving Family Bonds: \\ Examining Parent Perspectives in the Light of \\ Practice Standards for Out-of-Home Treatment
}

\author{
by \\ Adjoa D. Robinson, Ph.D. \\ Barbara J. Friesen, Ph.D. \\ Pauline Jivanjee, Ph.D. \\ Michael D. Pullmann, M.S. \\ Portland State University Research and Training Center \\ Portland State University \\ 1600 SW 4th Avenue, Suite 900 \\ Portland, OR 97201 \\ E-mail: adjoar@pdx.edu \\ Jean M. Kruzich, Ph.D. \\ University of Washington, Seattle
}

\footnotetext{
This research was conducted with funding from National Institute of Disability and Rehabilitation Research Grant H133B40021, the U.S. Department of Education, and the Center for Mental Health Services Substance Abuse and Mental Health Services Administration. The content does not necessarily represent the views or policies of the funding agencies.
} 
System of care principles emphasize models of service delivery that support family members, teachers, coaches, and other adult careers in helping children with serious emotional and behavioral disorders grow and learn in community settings while living at home. When the mental health needs of these children cannot be adequately addressed within the community, many of them are placed out of their home for the purpose of treatment. Although theory and research evidence support the importance of parent-child contact while children receive treatment when living away from the home (Bowlby, 1980; Grigsby, 1994; McWey, 2000), parents may find it difficult to maintain contact with their children and actively participate in their children's out-of-home treatment (Ainsworth, 1998; Alwon et al., 2000). This may be because of either family circumstances (e.g., lack of transportation) or agency policies or practices that inhibit contact.

This article addresses the experiences of families from across the United States with regard to parent-child contact when the children were placed out of their home for the purpose of receiving mental health treatment. In this article, the words parent, family, and family member are used interchangeably to refer to parents and primary caregivers of children with serious emotional disorders. Although support for parent-child contact may be found in theory and research across many fields, research in the field of children's mental health is very limited. Therefore, the following review draws on themes relevant to parents and children separated because of a variety of circumstances and relevant across fields of practice, including child welfare and health care.

\section{Statutory Rights}

When children are in out-of-home placement, parents retain all rights, including the right to be consulted for major decisions involving their child in care, unless they do not have legal custody (Hardin, 1985). In Troxel v. Granville (2000), the U.S. Supreme Court affirmed the fundamental right of fit parents ("a parent [who] adequately cares for his or her children" p. 2062) to make decisions concerning the care, custody, and control of their children as guaranteed under the 14th Amendment Due Process Clause. The Adoption and Child Welfare Act of 1980 required states to develop procedural safeguards to protect parents' rights to visit when children are removed from their home and placed in foster care. The only published national survey of state public agencies responsible for placement services found little evidence that states had fully complied (Hess \& Proch, 1986). Writing specifically about the child welfare system, Hess and Proch (1986) asserted that without clear statutory provisions stipulating the right of children and parents to maintain contact and the agency's responsibility to promote visiting, agency practices are unlikely to protect parent-child contact. Without more recent research on compliance with mandated protections at the state level, it is uncertain what kind of protection is currently afforded to parents and children.

\section{Theoretical Support}

Theoretical support for maintaining and promoting families' contact with their children in out-of-home placement is drawn from research on attachment and bonding. On the basis of extensive research, Bowlby (1980) provided evidence that children's capacity to form an attachment with a caregiving adult is the foundation of their capacity to form healthy relationships in later life and serves as a protective factor in dealing with stress. Attachment theory is now considered relevant to individuals at all stages of development (McWey, 2000). Attachments provide the continuity, stability, and mutuality necessary to healthy psychosocial development (McWey, 2000).

Greater attention to attachment theory highlights the need to promote parent-child contact (Grigsby, 1994; McWey, 2000). Whereas in earlier years family reunification was viewed only as physical return of the child to parental care, now, increasingly, reunification is seen on a continuum, with a recognition of the importance of family continuity regardless of whether the child returns home (Downs, Moore, McFadden, \& Costin, 2000; Jivanjee, 1999). Parental visiting enables children in foster care to divert emotional energy from feelings of abandonment to mastery of developmental tasks (Davis \& Ellis-McLeod, 1994).

\section{Research}


In addition to theoretical support for maintaining contact, researchers have also found demonstrable benefits from maintaining contact in foster care and medical hospital settings, and these findings hold promise for informing the field of children's mental health. Although causal pathways are unclear, foster care studies have found parental visiting to be significantly associated with shorter length of stay in foster care (Benedict \& White, 1991; Fanshel \& Shinn, 1978; Mech, 1985; White, Alber, \& Bitonti, 1996) and higher rates of family reunification (Davis, Landsverk, Newton, \& Ganger, 1996). In one study, children in foster care who regularly received parental visits had lower total behavior problem scores and fewer internalizing behaviors, such as depression and anxiety, than those with no or irregular contact (Cantos, Gries, \& Slis, 1997). Because face-to-face visits require parent and child to grapple with the reasons for the placement and their feelings about each other and their future relationship, such contact is seen as increasing the probability of reunification (Sanchirico \& Jablonka, 2000).

Results of studies of parent-child contact in medical hospitals have revealed that parental presence and participation in the hospitalized child's care can help the child. For example, Jones (1994) found that consistent and active participation by parents in routine care, emotional nurturance, and therapeutic procedures was associated with children's having higher activity levels and being less upset during painful procedures. In addition, studies of parental visiting during postoperative recovery found significantly decreased crying by children whose parents were present (Fiorentini, 1993).

Two studies in residential treatment settings are relevant to this review. In a study of incarcerated boys, Borgman (1985) found that more frequent visiting by families was associated with less major misconduct, and, for boys 15 years and older, visiting frequency was also significantly related to reduced moderate infractions. A second, more recent study (Landsman, Groza, Tyler, \& Malone, 2001) represents the only published research examining the effectiveness of a family-centered residential treatment model on permanency outcomes for children. The study included two groups from a single residential facility. The experimental group's intervention was designed to serve caregivers in addition to child residents and included skills training for parents, access to flexible funds, extended aftercare services, and active promotion of family involvement, decision making, and empowerment. The comparison group focused on the child as the primary recipient of the agency's standard residential treatment program, which included individual and group therapy; behavior management; and educational, psychiatric, medical, and recreational services. Results indicated that children in the family-centered experimental group had significantly shorter lengths of stay, and $49.0 \%$ were discharged home directly from residential treatment, compared with $19.0 \%$ of the comparison group.

These findings suggest the importance of further understanding the relationship between parent-child contact and outcomes in out-of-home treatment programs. The study presented here lays a foundation for this work by examining parents' experience of contact with their children in out-of-home treatment in light of prevailing national standards. Background information for this study was collected through focus groups conducted in 1996 and 1997. Groups were held with family members whose children were receiving out-of-home care and with residential treatment staff. The purpose was to learn about family and staff experiences and to identify barriers and supports to family involvement. During the focus groups, many family members expressed concern that contact with their children was limited, especially by inflexible rules and policies, including the application of point and level systems. On the basis of the results of the focus groups, a survey was designed to systematically gather data on family participation while the children were receiving treatment while living at home or in out-of-home settings. This article presents findings from an analysis of the responses of parents whose children were or had recently been in out-of-home placement for the purpose of treatment. The following questions guided the analysis: (a) What do parents report about parent-child contact during the initial stages of placement? (b) What do parents report about frequency of contact? (c) What do parents report about restrictions on contact with their child? and (d) How are parents' experiences in this cross-sectional study related to examples of current laws and standards regarding parent-child contact when the child is placed out of his or her home?

\section{Method}

\section{Sampling}

Eligible participants were parents or other caregivers with primary responsibility for youth aged 0 to 20 years who had received 3 months or more of treatment while living at home or 30 or more continuous days of out-of-home treatment for their emotional, behavioral, or mental disorders between September 1, 1996, and August 31, 1998. A sample of parents was recruited in two ways. First, randomly selected chapters of the Federation of Families for 
Children's Mental Health, a national family support and advocacy organization, assisted in recruitment. Using materials we had prepared, these family organizations sent letters to individuals on their mailing list describing the study, along with forms to return if they met the study criteria and were willing to participate. Additionally, family members on the mailing lists of a national research and training center were invited to participate in the study. Willing participants returned forms confirming eligibility to complete either the in- or out-of-home version of the questionnaire, which they returned by mail. Participation was anonymous, as questionnaires were returned with no identifying information. As an incentive, participants could order two complimentary publications that they chose from a list and returned separately from the questionnaire.

\section{Data Collection}

Data collection occurred in 1999-2000. A total of 867 willingness forms were returned; 646 in-home questionnaires and 221 out-of-home questionnaires were mailed to the participants. Reminder postcards were mailed at 2 and 4 weeks after the initial mailing of the questionnaire. A total of 489 usable surveys were returned by mail from 46 states, representing a $56.6 \%$ response rate. The returned questionnaires included $372(76.1 \%)$ of the in-home version and $117(23.9 \%)$ of the out-of-home version. There was no significant difference in return rates between in-home and out-of-home questionnaires. This analysis focuses on a subset of the sample, the responses from 102 parents whose children received out-of-home treatment in one of three settings: residential treatment centers (66.7\%), psychiatric hospitals/ units (20.6\%), and group homes (12.7\%).

\section{Measures}

Demographic information. Respondents were asked to indicate their age, race, sex, family income, highest level of education they had completed, familial relationship to the focal child, and custody status. We measured familial relationship by asking whether the respondent was a relative of the child by birth or adoption (mother, father, grandparent, other relative) or a nonrelative (foster parent or other). We measured custody status by asking whether the respondent, another relative, or a state agency had legal custody of the focal child at the time of placement. Respondents were also asked about characteristics of the child (age, race, sex, number of diagnoses, and type of out-of-home placement).

Contact and limits on contact. Questions from the Family Participation Survey used in the present analysis assessed frequency of and restrictions on contact. First, parents were asked whether contact with their child was limited for an initial period of adjustment (yes/no). We measured frequency of contact on an 8-point scale (from 1 $=$ never to $8=$ daily) by asking how often contact by telephone and visits (on campus, away from campus, and at home) occurred. We calculated total amount of contact by summing the midpoint of the frequency range for telephone contacts and visits. Parents were then asked whether, after the initial adjustment period, contact between child and family was restricted (yes/no) and, if so, what reason was given by the program. Contingencies on contact were measured in two ways. Parents were asked whether the out-of-home placement used a levels system in which their child earned points toward contact (yes/no) and to indicate from a list whether the program made contact dependent on the behavior of their child, other children in the living unit, or parent participation in therapeutic or educational services.

\section{Standards and Rules}

National accreditation and state licensing both involve monitoring various standards and requirements to assess service quality. Standards developed by national accrediting bodies, including the Council on Accreditation for Children and Family Services (COA; 2001a, 20016) and the Joint Commission on Accreditation of Health Care Organizations (JCAHO; 1997, 1999, 2002), were reviewed for policies related to parent-child contact that were in effect during the 1997-1998 time period that family members were surveyed (see Table 1). These organizations accredit behavioral health and health care organizations, including hospitals, residential treatment programs, independent living facilities, and group homes. Facilities and programs may choose to be accredited by more than one body. These national accrediting bodies are playing a progressively more important role in helping to ensure quality care. COA accredits or is in the process of accrediting over 1,500 organizations serving nearly 7 million children, youth, and families in the United States, Canada, Bermuda, and Puerto Rico (Joseph Seoane [COA's Director of Client and Trustee Relations], personal communication, August 13, 2003). JCAHO accredits more than 15,000 health care organizations serving a variety of populations (JCAHO, 1999, 2002).

Purchasers of care, both public and private, increasingly require accreditation for an agency to be eligible for contracts. States are also raising the value of accreditation by giving "deemed status" to nationally accredited 
organizations, which allows them to qualify for Medicaid reimbursement and exemption from relicensing surveys (Edmunds et al., 1997, p. 218). As of 1996, COA held deemed status in 22 states, which indicates that the state accepts accreditation as a measure of adequate quality and consumer protection (cited in Edmunds et al., 1997). Recent reports indicate that states are increasingly accepting accreditation in lieu of state certification and relicensure (Klarberg, 2003). The standards in Table 1 fall into three categories: (a) overall policies and practices related to parent-child contact, (b) visiting policies, and (c) restrictions related to visiting and other forms of contact. In the following sections of this article, we examine our results in relation to these out-of-home treatment standards.

\section{Table I}

\section{Examples of Standards}

\section{Subject}

\section{Organization}

\section{Contact}

The organization makes ongoing efforts to involve the family in services by maintaining contact between the family and the resident unless clearly contraindicated by the case. All children and adults in out-of-home care have the right to have a telephone conversation with family members, as appropriate to the service plan.

Visiting policy

All service plans for children or youth in out-of home care specify visitation arrangements, unless Council on Accreditation for Children and Family contraindicated, including location and frequency, and all children and adults in out-of-home care have the right to visit their family in their family's home and receive visits from family and friends, as appropriate to the service plan.

\section{Restriction}

If therapeutic indications necessitate restrictions on visitors, mail, telephone calls, or other forms of Joint Commission on Accreditation of Health Care communication, those restrictions are evaluated for

\section{Organizations}

their therapeutic effectiveness. All such restrictions are fully explained and determined with the participation of the individuals served and, when appropriate, the individuals' family.

\section{Services}

\section{Services} s 


\section{Data Analysis}

Analysis included statistics describing the respondents and focal child. Frequencies and percentages were calculated for amount of contact and restrictions on contact. Bivariate analyses were performed to investigate relations among variables in the study. Following a description of the sample, findings are presented in relation to each research question. Standards are presented first, followed by survey findings.

\section{Results}

\section{Description of Sample}

A description of the sample is shown in Table 2. Eight male parents and 94 female parents reported on 74 male and 28 female children. Most of the respondents were birth mothers (68.6\%) or adoptive mothers (18.6\%). Although the U.S. median household income range was relatively high ( $\$ 35,000-\$ 44,999$ per year), 32.0\% of respondents had a very low family income (less than $50.0 \%$ of the U.S. median), and one half of these families were at or below the federal poverty threshold (Federal Register, 1999; U.S. Census Bureau, 2000). Seventy-nine percent had legal custody of the child at the time of placement, and, of those without legal custody, the majority (52.0\%) reported relinquishment of parental rights as a prerequisite for state funding of treatment services.

The average accumulated length of out-of-home placement over the 2-year study period was 13.8 months (SD = 7.6). Of all children, $65.7 \%$ were reported to have had just one out-of-home placement. Nearly $90 \%(89.1 \%)$ of the children had more than one diagnosis $(M=3.8, \mathrm{SD}=2.1)$. The most common diagnoses reported were attention-deficit/hyperactivity disorder (49.0\%), bipolar disorder (42.2\%), and oppositional defiant disorder (40.2\%). In addition to general demographic information describing parent and child, respondents were asked the age at which the child first experienced difficulties $(M=6.1$ years, $S D=3.8)$ and first received mental health services $(M=7.2$ years, $S D=3.8)$. We created a severity rating scale by adding the number of diagnoses reported and the number of years the child had been experiencing difficulties (the difference between a child's current age and the age at which he or she began experiencing difficulties).

\section{Parent-Child Contact: Initial Stages and Placement}

Standards and policies addressing contact immediately after placement. Concerns expressed by parents during focus groups prompted the inclusion of questions specifically addressing parent-child contact immediately following placement, as many parents said that contact with their child was limited during an initial period following the child's entry. The standards we examined do not, however, provide policies for different stages of a placement; rather, they are assumed applicable for the entirety of a child's stay (see Table 1). According to the policies and regulations examined, organizations must have written policies guaranteeing the right of parents to communicate with and visit their children and have service plans developed in cooperation with parents that specify frequency, length, and location of visits and telephone calls (COA, 2001; JCAHO, 1997).

Parent reports on restrictions immediately after placement. Nearly $60.0 \%$ of parents reported that parent-child contact was limited for an initial period of adjustment after placement. This period lasted 1-8 weeks, with the largest percentage of parents who had limitations on contact immediately after placement reporting periods of 1 (23.5\%), 2 (25.5\%), or $4(33.3 \%)$ weeks. There was no significant difference in restrictions on the basis of child age or treatment setting. Parents of children less than 11 years of age were equally likely to report restrictions on initial contact as those with older children, $X^{2}(1, N=102)=0.08, p=.77$. Parents with children in the three treatment settings (residential, psychiatric hospital, and group home) reported limits on initial contact with equal frequency, $X^{2}(2, N=102)=2.96, p=.30$. However, noncustodial parents were more likely to report such restrictions than custodial parents, $X^{2}(1, N=99)=5.50, p<.05$, even though only $14.0 \%(n=3)$ stated reasons such as abuse or neglect for not having custody.

Parent reports of the reasons given by facility personnel for restricting initial contact fell into two categories. The primary explanation reported was that the child "needed time to adjust" or to "settle in." The second most frequently mentioned reason was that visits and other forms of contact were considered a privilege that had to be earned; for example, a parent noted that her child was "not on level for visits." 
Table 2

Demographic Characteristics $(\mathrm{N}=102)$

\begin{tabular}{|c|c|c|c|c|}
\hline Variable & $M$ & $S D$ & $\%$ & Range \\
\hline & Child & & & \\
\hline \multicolumn{5}{|l|}{ Sex } \\
\hline Male & & & 72.5 & \\
\hline \multicolumn{5}{|l|}{ Race } \\
\hline White & & & 80.0 & \\
\hline Non-White & & & 20.0 & \\
\hline Child's age in years & 15.9 & 3.4 & & $3-23$ \\
\hline Age of onset & 6.1 & 3.8 & & $1-16$ \\
\hline Age first received services & 7.2 & 3.8 & & $2-16$ \\
\hline
\end{tabular}

\section{Respondent}

Sex

Female

Race

White

Non-White

Age in years

Education level

HS diploma/GED

Bus/trade/some college

College degree

Marital status

Married/marriage-like arrangement

Median family income

Related to child

Biological/adoptive mother
92.2

90.0

10.0

45.0

6.7

29-67
13.7

33.3

53.0

61.8

$\$ 35,000-$

$\$ 44,999$
$<\$ 5,000-$

$\$ 75,000$

Note. $\mathrm{HS}=$ high school; GED = general education diploma; Bus = business. 
Standards and policies addressing frequency of contact. Policies and guidelines addressing frequency of parentchild contact emphasize both regularity and flexibility. One example is the Colorado State Department of Health Care Policy and Financing (CDHPF; 2001) administrative code, which states, "Every client has the right to have frequent and convenient opportunities to meet with visitors. Each client may see his or her custodial parent or his or her children at any time" (sect. 8.765.442K).

Parent reports on frequency of contact. Respondents reported that telephone contact occurred most frequently, with $88.2 \%$ of parents reporting telephone contact once a week or more, whereas $63.0 \%, 33.0 \%$, and $23.7 \%$ reported that visits occurred once a week or more on campus, off campus, and at home, respectively. Total amount of contact varied by child's age, distance from home to placement, and limits on contact. Younger children had more contact with their family $(r=-.289, \mathrm{p}<.0 \mathrm{l})$, as did children in treatment facilities closer to home $(r=$ $-.255, p<.05)$. There were no significant differences in frequency of contact on the basis of the child's sex, race, or severity of condition, nor were there significant differences on the basis of respondent characteristics (sex, race, age, income, education, custody status, or marital status).

\section{Parent-Child Contact: Restrictions on Contact}

Standards and policies addressing restrictions on contact. Regulatory bodies require that restrictions on contact be fully explained, be disclosed prior to placement, demonstrate benefit to the individual served, and be determined with the participation of the individual and her or his family when appropriate (JCAHO, 2002). Regular reviews for therapeutic effectiveness are required when restrictions are imposed (COA, 2001). Finally, circumstances under which restrictions on parent-child contact may be implemented are limited to three conditions judicial orders, potential for child endangerment, and the possibility of adverse effects on the child's mental health and development (COA, 2001; CDHPF, 2001; Massachusetts General Laws, 1997). Restrictions as a consequence of group punishment are considered undesirable, nontherapeutic, and counterproductive by some (Child Welfare League of America, 1991; VanderVen, 1995); however, regulatory bodies in the United States have only begun to address this issue.

Parent reports about restrictions on contact. Many parents reported that after an initial period of adjustment, subsequent parent-child contact was contingent on the child's behavior, sometimes in connection with the use of point and level systems. Many programs use point and level systems as a behavior management technique. Points are earned for exhibiting desirable behavior and may be deducted for failure to follow rules (VanderVen, 1995). Accumulation of points advances children to different levels, which are tied to privileges such as participation in activities, opportunities for autonomy, and, in many cases, visits with family.

The majority (79.4\%) of parents reported at least one type of restriction on contact. Almost $40 \%$ (39.6\%) of respondents reported restrictions on telephone calls, $35.6 \%$ of respondents reported restrictions on day visits at the facility, $46.9 \%$ of respondents reported restrictions on day visits away from the facility, and $60.0 \%$ of respondents reported restrictions on home visits. Telephone contact and visits were less frequent for those reporting limits than for those without limits. For telephone contact, the difference was statistically significant, $t(100)=2.15, p<.05$. The likelihood of limits on contact varied significantly by child gender, parent marital status, and parent custodial status (see Table 3). Parents of girls and single parents were more likely to report restrictions on contact. Parents who did not have legal custody of their children were also more likely to report restrictions.

Approximately half (51.0\%) of the respondents reported restrictions on parent-child contact on the basis of a point and level system. Parents made comments such as, "He was allowed to call weekly unless he lost the privilege," and, "Contact was restricted by individual and group behavior." Fifty-nine percent of respondents reported that contact with their child was dependent on their child's behavior. Such contingencies based on the child's behavior varied by severity score and family income. Parents of children with less severe problems were more likely to report that contact with their children was contingent on the child's behavior than those who did not report contingencies based on their child's behavior, $t(99)=2.02, p<.05$, and, of parents who earned very low incomes (less than $50.0 \%$ of the U.S. median), $82.4 \%$ reported such contingencies compared with $54.2 \%$ of those who earned more $(n=100$; odds ratio $[\mathrm{OR}]=1.5,95 \%$ confidence interval $[\mathrm{Cl}]=1.05,14.75)$. Some parents $(11.8 \%)$ were required to participate in educational or therapeutic services as a condition for contact with their children. 
Parents of children younger than 11 years of age $(n=12)$ were five times more likely to report this requirement than parents of older children $(n=90 ;$ OR $=4.0,95 \% \mathrm{Cl}=1.26,20.83)$.

Sometimes restrictions had nothing to do with either the child's or the parent's behavior. Sixteen percent of parents reported that parent-child contact was contingent on the behavior of peers in the living or treatment unit. One parent commented that on one occasion the "group [was] on lockdown (they cancelled my visit that afternoon after [the] hotel was confirmed and paid)."

Reported reasons for limiting contact fell primarily into four main categories: individual staff discretion, restrictive facility policies, behavior modification programs, and maintenance of the "therapeutic" environment. Responses revealed the perception on the part of some parents that limits were imposed arbitrarily. Some parents felt that "staff choice" or "convenience for staff' and "subjective observations [and/ or] staff opinions" were the primary determinants. Comments by parents also indicated restrictive policies regarding amount of contact. One parent said, "[There was a] limit of 2 (or fewer) calls per week"; another reported, "Visiting hours were limited to Saturday or Sunday from 1-4 p.m." Visits were thought to be earned "through good behavior." Parents reported that calls were restricted, "so as not to interfere with the group's flow of events/daily schedule" and that visits were encouraged on weekends only, "otherwise visits interfered with [the] therapeutic process."

\section{Table 3}

Significant Differences in Likelihood of Limits on Contact by Demographic Characteristic: Odds Ratio Analysis

\begin{tabular}{|c|c|c|c|c|c|c|}
\hline \multirow[b]{2}{*}{$\begin{array}{l}\text { Type of } \\
\text { limitation }\end{array}$} & \multirow[b]{2}{*}{ Comparisons } & \multirow[b]{2}{*}{ Limit (\%) } & \multirow[b]{2}{*}{ No limit (\%) } & \multirow[b]{2}{*}{ Odds ratio } & \multicolumn{2}{|c|}{$95 \% \mathrm{Cl}$} \\
\hline & & & & & Lower & Upper \\
\hline \multirow[t]{4}{*}{$\begin{array}{l}\text { Telephone } \\
\text { contact }\end{array}$} & Parents of boys & 31.5 & 68.5 & & & \\
\hline & Parents of girls & 60.5 & 39.3 & $0.30^{a_{\star}}$ & 0.12 & 0.74 \\
\hline & Single parents & 51.3 & 48.7 & & & \\
\hline & Married parents & 32.3 & 67.7 & $2.11^{b_{* \star}}$ & 0.97 & 5.04 \\
\hline \multirow[t]{2}{*}{$\begin{array}{l}\text { Visits away } \\
\text { from facility }\end{array}$} & $\begin{array}{l}\text { Noncustodial } \\
\text { caregivers }\end{array}$ & 73.7 & 26.3 & & & \\
\hline & $\begin{array}{l}\text { Custodial } \\
\text { caregivers }\end{array}$ & 39.5 & 60.5 & $4.29^{a_{\star}}$ & 1.40 & 13.16 \\
\hline
\end{tabular}

Note. $\mathrm{Cl}=$ confidence interval.
${ }^{a}$ Tests of significance were based ${ }^{b}$ Tests of significance on Pearson chi-square. were based on Fisher's

${ }^{\star *} p<.05$ (one-tailed). ${ }^{*} p<.01$

(two-tailed). 


\section{Discussion}

Despite good reasons to promote parent-child visits, many organizations still restrict contact between children and their parents. Contact during the initial period is ostensibly limited to assist in the child's adjustment. Although accrediting guidelines do not address initial contact, contemporary child welfare literature highlights the importance of actively preserving children's attachment to their parents and minimizing the stress and trauma of separation (Downs et al., 2000). Regular and frequent parental visitation is widely recognized as crucial to maintaining attachments (Grigsby, 1994; McWey, 2000). Particularly troublesome is that our findings indicate that initial restrictions on contact were applied equally to children regardless of age and setting.

There are no empirical studies that support limiting parent-child contact as a method of helping children adjust to out-of-home settings. In the first half of the 1900 s, prominent theoretical models conveyed the notion that parents were to blame for their child's difficulties, with children needing to be removed from the noxious influence of their family (VanderVen, 1991). Foster parents and child care workers may interpret a child's emotional distress before, during, or after visits as evidence for the negative effect of parent-child contact instead of recognizing the emotional pain that is part of the process involved in separation and loss (Coleman, 1999; Hess, 1988). Although the child welfare and mental health fields have moved away from a "child rescue" philosophy and toward a new paradigm that emphasizes the preservation of family ties even when family members need to be separated (Coleman, 1999; Johnson, 1999), parents' experiences suggest that vestiges of earlier theories continue to shape actual practices. This is especially true regarding the issue of parent-child contact.

After the initial period, contact often becomes contingent on the behavior of the child, parent, or unit group in the facility. Many parents reported experiences in contrast to approaches embodied in regulations and administrative rules, including the finding that family contact was treated as a privilege to be earned or as a contingency based on child, parent, or unit group behavior. There is no mention of the undesirability of using child misbehavior or parent attendance at a parent education class as a necessary precondition or contingency for parental contact with the child. In contrast, England's administrative regulations list any restrictions or refusal of visits/communications as unacceptable practices under the Children Act of 1989 , and such restrictions are permitted only when specified as a court requirement (Whittaker, Archer, \& Hicks, 1998).

Although family contact as a privilege is not a feature of all point and level systems, over half the respondents identified point and level systems as the reason for contact being limited. A significant problem with point and level systems is that they are usually not individualized. They govern a host of behaviors required of all children, thus compromising sensitivity to cultural and other kinds of differences among children (VanderVen, 2000). This "one size fits all" approach contradicts the Child Welfare League of America's (1991) Standards of Excellence for Residential Group Care Services, which stated that group punishment is undesirable and that behavioral expectations should be individualized according to a child's age, maturity level, and ability to manage his or her own behavior. JCAHO (2002) has recently made changes to its behavioral health care standards that emphasize individualization of interventions and prohibit group contingencies based on a single individual's behavior. In residential settings where there has been an emphasis on maintaining control over residents and minimizing staff discretion (Moses, 2000), more highly trained staff are required to implement individualized approaches to treatment. Individualized services in accordance with the unique needs and potentials of each child are a key feature of systems of care for children with serious emotional disorders and their family (Stroul \& Friedman, 1986) and are emphasized in wraparound services (VanDenBerg, 1999).

Although agencies' policies regarding restrictions on contact may be applied equally to all residents, it is unlikely that the distress of parents and children is equally distributed. A study of hospitalized school-age children found that children from low-income families reported significantly higher levels of fear of separation from family, fear of interactions with health care providers, and fear of the health care environment (Hart \& Bossert, 1994). In another study, ethnic minority mothers of hospitalized children expressed the desire for significantly more control over their children's care than did nonminority mothers, a finding interpreted by the author as supporting the need to provide protection in a setting staffed primarily by people who do not reflect the mothers' ethnicity (Schepp, 1992). Although Schepp's study focused on out-of-home treatment for medical care, it seems likely that these issues might also be a concern for ethnically diverse families whose children are placed in residential treatment facilities, which are staffed predominantly by nonminority individuals. 


\section{Limitations of the Study}

The limitations of this study are implicit in its sampling method and design. Because there are no listings that identify families whose children have received mental health services, we created a sampling frame on the basis of lists from organizations that provide services and supports to this population. Although our sampling strategy allowed us to survey a national sample of parents, the sampling frame was probably not fully representative of the population of interest, caregivers of children with serious emotional problems. Studies have found that parents on either end of the income spectrum tend not to be members of support organizations (Koroloff \& Friesen, 1991; Turnbull \& Turnbull, 1997). Our sample is more ethnically homogeneous and better educated than the general population and, in addition, was recruited from family advocacy organizations. However, there is no reason to expect that parents who are less educated and more ethnically diverse would have less difficulty maintaining contact with their children in out-of-home care. Parents affiliated with a family advocacy organization are likely to be more active in their efforts to maintain contact with their children. Parents who are not involved with a family advocacy organization may be unaware of their rights to contact if staff does not inform them.

Until this study is replicated with other populations (families not affiliated with family support organizations), our findings should not be generalized to the population of all families whose children have emotional, behavioral, or mental disorders. It is likely that parents who answered our survey had more positive experiences than those who were not members of family advocacy organizations. Parents may have different experiences from state to state. Nonetheless, these findings point to a number of areas that have received scant attention in the mental health literature.

\section{Implications}

Accrediting and licensing bodies have a critical role in developing standards that address issues of great concern to children and families who use out-of-home treatment settings. Accreditation and licensing standards should reflect the most empirically sound and current theory and knowledge base for informing agency practice (Class, 1968, as cited in Costin, Bell, \& Downs, 1991). To ensure appropriate standards and regulations for parent-child contact in out-of-home treatment, parents must have an authentic voice in the adoption of such regulations (Costin et al., 1991). Providing guidance to agencies in the area of parent-child contact requires specific attention to agency policies and practices that directly affect parent-child contact. However, recent demands for multiple changes in practices resulting from managed care philosophies may contribute to the resistance of residential treatment facilities to changes that require new ways of providing services (Costin et al., 1991; Kennard, 1997).

In addition to the influence of accreditation standards on policies and practices in out-of-home treatment facilities, practices are shaped by the attitudes, knowledge, and skills of administrators as well as supervisory-level and front-line staff (Costin et al., 1991). According to Landsman et al. (2001), the implementation of family empowerment and family development concepts in residential treatment has been inconsistent and sporadic. Carlson, Barr, and Young (1994) noted the need for residential treatment staff to work more closely with the families of children in their care. Our findings indicate the wide variability of visiting practices from setting to setting. There is evidence in the literature that variability of work experience, training, and qualifications among residential treatment staff is related to low professional status and compensation and high rates of staff turnover (Costin et al., 1991). A study by Coleman (1999) suggests that training in family-centered practice is correlated with more positive staff attitudes toward parents. Training and professional education may enhance staff members' theoretical understanding of the effects of parent-child contact in maintaining family relationships and provide pragmatic knowledge of the effects of regular contact on reducing the length of placement and improving long-term outcomes. For some staff, who are long accustomed ships through carefully crafted policies and practices to acting in place of parents (VanderVen \& Stuck, related to parent-child contact.1996), such training may involve a major shift in thinking. Training efforts also need to support affective as well as cognitive changes on the part of staff, with empathy-building exercises as an important part of helping shift staff attitudes to a new paradigm of family involvement (Alwon et al., 2000). In addition to changes in staff attitudes and knowledge about family relationships, concrete strategies to promote parent-child contact are needed, with special attention to cultural and social class differences between staff and family members (Braziel, 1996; VanderVen \& Stuck, 1996).

Past studies have indicated that agency policies are powerful influences on staff attitudes and practices that can either support or constrain family involvement in health and mental health settings (Giganti, 1998; Hess, 1988). Further research is needed to identify mediating influences, including visiting policies and opportunities for family participation in relationship to child outcomes. Identification of individual and organizational factors that affect parent and child distress when children are placed in out-of-home treatment is needed to help child welfare and 
mental health providers develop interventions that are most supportive of parent-child relationships and best able to decrease the distress associated with separation. Special attention needs to be paid to identifying stressors for families of color whose historical experience with societal institutions dominated by nonminority personnel may accentuate the stress and increase the need for interventions that respond to culturally relevant factors.

\section{Conclusion}

These findings point to a number of areas that have received little attention in the mental health literature. Widespread restrictions on initial contact and agency policies that treat parent child contact as a privilege that needs to be earned highlight the gap between the espoused philosophy of family centeredness and actual practice in out-of-home settings. Our findings reveal areas to be addressed if family-centered services are to be implemented consistently in residential settings. The evidence from research studies overwhelmingly supports the importance of preserving parent-child relationships in out-of-home treatment. The challenge is for accreditation bodies and advocacy organizations to heed family voices and hold residential treatment programs accountable for strengthening and maintaining parent-child relation.

\section{References}

Adoption and Child Welfare Act, 42 U. S. C. § 620-629, 670-679 (1980).

Ainsworth, F. (1998). Family centered group care practice: Model building. Child and Youth Care Forum, 27(1), 59-69.

Alwon, F. J., Cunnigham, L., Phills, J., Reitz, A., Small, R., \& Waldron, V. M. (2000). The Carolinas project: A comprehensive intervention to support family-centered group care practice. Residential Treatment for Children and Youth, 17(3), 47-62.

Benedict, M. L, \& White, R. B. (1991). Factors associated with foster care and length of stay. Child Welfare, 70, 45-58.

Borgman, R. (1985). The influence of family visiting upon boys' behavior in a juvenile correctional institute. Child Welfare, 64, 629-637.

Bowlby, J. (1980). Developmental psychiatry comes of age. American Journal of Psychiatry, 145, 1-10.

Braziel, D. J. (1996). CWLA family-focused assessment tool. In D. J. Braziel (Ed.). Family focused practice in out-of-home care: A handbook and resource directory (pp. 167-188). Washington, DC: CWLA Press.

Cantos, A. L., Gries, L. T., \& Slis, V. (1997). Behavioral correlates of parental visiting during family foster care. Child Welfare, 76, 309-329.

Carlson, B. E., Barr, W. B., \& Young, K. J. (1994). Factors associated with treatment outcomes of male adolescents. In G. Northrop (Ed.). Applied research in residential treatment (pp. 39-58). New York: Haworth Press.

Child Welfare League of America. (1991). Standards of excellence for residential group care services. Washington, DC: Author.

Coleman, F. C. (1999). Staff attitudes toward family involvement and reunification for children in residential treatment centers (Doctoral Dissertation, Pace University, 1999). Dissertation Abstracts International, 60, 5221.

Colorado State Department of Health Care Policy and Financing. (2001). Staff manual: Vol. 8. Medical assistance. Denver: Division of Mental Health, Colorado Department of Human Services.

Costin, L. B., Bell, C. J., \& Downs, S. W. (1991). The regulation of children's out-of-home care. In Child welfare: Policies, practice (4th ed., pp. 100-128). New York: Longman. 
Council on Accreditation for Children and Family Services. (2001a). Ethical practice, rights, and responsibilities (7th ed.) [Brochure]. New York: Author.

Council on Accreditation for Children and Family Services. (2001b). Guidelines to COA accreditation (7th ed.). New York: Author.

Davis, I. P., \& Ellis-MacLeod, E. (1994). Temporary foster care: Separating and reunifying families. In J. Blacher (Ed.), When there's no place like home: Options for children living apart from their natural families (pp.123-161). Baltimore: Brooks.

Davis, I. P., Landsverk, J., Newton, R., \& Ganger, W. (1996). Parental visiting and foster care reunification. Children and Youth Services Review, 18, 363-382.

Downs, S. W., Moore, E., McFadden, E. J., \& Costin, L. B. (2000). Child welfare and family services: Standards and policies and practice (6th ed.). Needham Heights, MA: Allyn \& Bacon.

Edmunds, M., Frank, R., Hogan, M., McCarty, D., Robinson-Beale, R., \& Weisner, C. (Eds.). (1997). Managing managed care: Quality improvement in behavioral health. Washington, DC: National Academy Press.

Fanshel, D., \& Shinn, E. (1978). Children in foster care: A longitudinal investigation. New York: Columbia University Press.

Federal Register. (1999). Annual update of the Health and Human Services poverty guidelines (No. fr24fe98-89). Washington, DC: Department of Health and Human Services.

Fiorentini, M. F. (1993). Evaluation of a new program: Pediatric parental visitation in the post anesthesia care unit. Journal of Post Anesthesia Nursing, 8, 249-256.

Giganti, A. W. (1998). Families in pediatric critical care: The best option. Pediatric Nursing, 24, 261-265.

Grigsby, R. K. (1994). Maintaining attachment relationships among children in care. Families in Society, 75, 269-276.

Hardin, M. (1985). Families, children, and the law. In J. Laird \& A. Hartman (Eds.), A handbook of child welfare: Context, knowledge, and practice (pp. 213-236). New York: Free Press.

Hart, D., \& Bossert, E. (1994). Self-reported fears of hospitalized school-age children. Journal of Pediatric Nursing, 9(2), 83-90.

Hess, P. (1988). Case and context: Determinants of planned visit frequency in foster family care. Child Welfare, 67, 311-326.

Hess, P., \& Proch, K. (1986). How the states regulate parent-child visiting: A survey of the states shows great diversity. Public Welfare, 7(4), 41-55.

Jivanjee, P. (1999). Parent perspectives on family involvement in therapeutic foster care. Journal of Child and Family Studies, 8, 451-461.

Johnson, M. N. (1999). Multiple dimensions of family-centered practice in residential group care: Implications regarding the roles of stakeholders. Child \& Youth Care Forum, 28(2), 123-139.

Joint Commission On Accreditation of Health Care Organizations. (1997). 1997-1998 comprehensive accreditation manual for behavioral healthcare. Oakbrook Terrace, IL: Author

Joint Commission On Accreditation of Health Care Organizations. (1999). 1999-2000 comprehensive accreditation manual for behavioral health care. Oakbrook Terrace, IL: Author. 
Joint Commission on Accreditation of Health Care Organizations. (2002). Revised behavior management and treatment standards approved for behavioral health care. Perspectives, 22(9), 13-15. Oakbrook Terrace, IL: Author.

Jones, D. C. (1994). Effect of parental participation on hospitalized child behavior. Issues in Comprehensive Pediatric Nursing, 17(2), 81-92.

Kennard, D. (1997). A change for the agents of change. Residential Treatment for Children and Youth, 14(4), 31-32.

Klarberg, R. (2003). Report from the CEO/president report summary 2003. Retrieved December 2003 from http://www.coanet.org/CEOletterSO3.pdf

Koroloff, N. M., \& Friesen, B. J. (1991). Support groups for parents of children with emotional disorders: A comparison of members and non-members. Community Mental Health Journal, 27, 265-279.

Landsman, M., Groza, V., Tyler, M., \& Malone, K. (2001). Outcomes of family-centered residential treatment. Child Welfare, 80, 351-379.

Massachusetts General Laws ch. 123, §23 (1997).

McWey, L. (2000). I promise to act better if you let me see my family: Attachment theory and .foster care visitation. Journal of Family Social Work, 5(1), 91-105.

Mech, E. V. (1985). Parental visiting and foster placement. Child Welfare, 64, 67-72.

Moses, T. (2000). Attachment theory and residential treatment: A study of staff-client relationships. American Journal of Orthopsychiatry, 70, 474-490.

Sanchirico, A., \& Jablonka, K. (2000). Keeping foster children connected to their biological parents: The impact of foster parent training and support. Child and Adolescent Social Work Journal, 17, 185-203.

Schepp, K. G. (1992). Correlates of mothers who prefer control over their hospitalized children's care. Journal of Pediatric Nursing, 7(2), 83-89.

Stroul, B. A., \& Friedman, R. M. (1986). A system of care for severely emotionally disturbed children and youth. Washington, DC: Georgetown University Child Development Center, CASSP Technical Assistance Center.

Troxel v. Granville, 530 U. S. 57, 120 S. Ct. 2054 (2000).

Turnbull, A., \& Turnbull, H. R. (1997). Families, professionals, and exceptionality: A special partnership. Saddle River, NJ: Merrill.

U.S. Census Bureau. (2000). Current population reports, money income in the United States: 1999. Washington, DC: U.S. Government Printing Office.

VanDenBerg, J. (1999). History of the wraparound process. In B. J. Burns \& S. K. Goldman (Eds.), Systems of care: Promising practices in children's mental health, 1998 series: Volume 4. Promising practices in wraparound for children with .serious emotional disturbance and their families (pp. 19-2G). Washington, DC: Center for Effective Collaboration and Practice, American Institutes for Research.

VanderVen, K. (1991). Working with families of children and youth in residential settings. In J. Beker \& Z. Eisikovits (Eds.), Knowledge utilization in residential child and youth care practice (pp. 117-128). Washington, DC: Child Welfare League of America.

VanderVen, K. (1995). "Point and level systems": Another way to fail children and youth. Child and Youth Care Forum, 24, 345-366.

VanderVen, K. (2000). Cultural aspects of point and level systems. Reclaiming Children and Youth, 9(1), 53-59. 
VanderVen, K., \& Stuck, E. (1996). A model of agency and child and youth care worker preparation for family-centered residential programs. In D. J. Braziel (Ed.), Family-focused practice in out-of-home care: $A$ handbook and resource directory (pp. 117-128). Washington, DC: Child Welfare League of America.

White, M., Alber, E., \& Bitonti, C. (1996). Factors in the length of foster care: Worker activities and parent-child visitation. Journal of Sociology and Social Welfare, 23(2), 75-84.

Whittaker, D. S., Archer, L., \& Hicks, L. (1998). Working in children's homes: Challenges and complexities. Chichester, England: Wiley. 